\title{
]AH[Brexit and the future of English in Europe
}

\begin{abstract}
]au[KINGSLEY BOLTON*AND DANIEL R. DAVIS ${ }^{* *}$
Jabh[ABSTRACT: ]abs[In this issue of the journal we present a forum on a current topic of key sociolinguistic interest to both linguists and the wider population in Europe and elsewhere, that is the expected future of the English language in a reconfigured Europe after the impending British exit (or 'Brexit') from Europe. The key document discussed in this forum is a position paper from Marko Modiano, which has drawn a number of responses from leading linguists across the field of world Englishes. We are sincerely thankful to Modiano for initiating this forum, and grateful also to all those that have contributed their responses to his article, which has resulted, we believe, in an insightful and lively discussion of the sociolinguistics of English and multilingualism in contemporary Europe.
\end{abstract}

\section{]ha[INTRODUCTION}

]ro[When the results of the referendum on Britain's membership of the European Union were declared in June 2016, the reaction of many UK and EU citizens was one of shock and bewilderment. The vote was seen by many as a reactionary response signaling a rejection of open borders and an open immigration policy, as well as an almost incomprehensible denial of the many benefits of EU citizenship, at the levels of economic, social and cultural cooperation and mutual understanding. Whatever the politics of the referendum vote, one immediate repercussion in the UK press was a substantial amount of somewhat sensational reportage on the future of the English language in Europe. Newspapers headlined the dire news that 'English should be BANNED in Brussels after Britain leaves' (from the Daily Express), and that there were moves afoot to replace English by French as in a 'Push to bid adieu to English as EU's lingua franca' (from the Financial Times). The FT article quoted Jean-Luc Melenchon, a French member of the European parliament, as tweeting that 'English can no longer be the third working language of the European Parliament', while Robert Ménard, another French politician, declared that, following the vote, 'The English language has no legitimacy in Brussels'. The usually sober and restrained Financial Times speculated thus on the issue at hand:

] ex[It was long a source of irritation to the French that the language of a country that joined the bloc late and was always ambivalent about its institutions so dominated EU business. [...] But if Brexit happens, English would be an official language of only two EU member states - Ireland and Malta, whose combined population of just over $5 \mathrm{~m}$ is a tiny fraction of the EU's total of $500 \mathrm{~m}$. The anti-English camp wonder how a language soon to be spoken by less than 1 per cent of the EU's population can remain its lingua franca. (Chazan \& Brunsden 2016)

]fo[The-same article went on to note that the ascendancy of English was of rather recent origin, and that until the early 1990s, the French language had dominated many of the EU's

]audet[ ${ }^{*}$ Nanyang Technological University, School of Humanities and Social Sciences, Division of Linguistics and Multilingual Studies, 14 Nanyang Drive, Singapore 637332, Singapore.E-mail: kbolton@ntu.edu.sg

** University of Michigan-Dearborn, Department of Language, Culture, and Communication, 4901 Evergreen Road, Dearborn MI 48128-2406 USA. E-mail: davisdr@umich.edu.

This is the author manuscript accepted for publication and has undergone full peer review but has not been through the copyediting, typesetting, pagination and proofreading process, which may lead to differences between this version and the Version of Record. Please cite this article as doi:

10.1111/weng. 12263 .

This article is protected by copyright. All rights reserved. 
proceedings. Another article in the influential Wall Street Journal also appeared to exaggerate the linguistic consequences of the Brexit referendum, with a headline that asserted that 'English loses currency as Europe's lingua franca after Brexit vote'. The WSJ commentary expounded on the topic in an equally alarmist mode, declaiming that:

] ex[The UK's departure from the European Union will erode the status of the English language in EU institutions to the benefit of French and German, with the bloc's executive arm already moving to ditch English from some of its official communications. [...] more meetings will be held in French or Germanexcluding those who have focused on English as their main foreign language. Others pointed out that focusing on French and German will further entrench the power of Berlin and Paris, excluding countries in the EU's north, south and east that are already losing a political ally. (Steinhauser 2016)

]fo[However, despite the somewhat strident tone of the headline, the same article finally went on to conclude that, at a de facto level, English is likely to remain an official language, as it is 'the main language used by the many non-native English speakers in Brussels, including EU officials, lawyers, lobbyists and journalists'.

]p[Such discussions in the press were largely authored by non-linguists, and so, when Marko Modiano submitted his article on the topic (this issue) earlier this year, the Editors of World Englishes saw an excellent opportunity for other linguists to express their opinions on this issue. Accordingly, Modiano's article was circulated among this forum's contributors, and their responses are now presented in this issue of the journal. We hope that this introductory article by the co-editors of World Englishes will help to contextualize this debate in the sociolinguistics of contemporary Europe, and to serve as an introduction to the forum.

\section{]ha[MODIANO ON ENGLISH AND BREXIT}

]ro[In the Introduction to his article, Marko Modiano (this issue) makes it clear that a major inspiration for his analysis of the European context has been the 'liberation linguistics' of Braj B. Kachru, arguing that ' $[\mathrm{t}]$ his dynamic polymodel also has relevance for how we conceptualize English as it is used as a second language in continental Europe', as English has now become 'a second language used freely among the citizens of the EU, within the EU, in settings where interlocutors do not share a common L1'. Modiano further argues that English should now be regarded as 'a continental European language', given the fact that statistics now attest to the spread of English throughout the whole of Europe, explaining that:

] ex[Given the dramatic spread of English throughout the European Union in recent decades, it is probably no longer appropriate to describe English in the EU in terms of an Expanding Circle variety/or varieties, but rather something different - as a 'second language' or in terms of continental Europe as a developing Outer Circle context. After all, English within the EU now has extensive governmental, educational, informational, and work-related functionality, as well as increasing utility in the creation of intellectual properties. (Modiano, this issue)

]fo[The exit of Britain from the EU, he suggests, will now create 'the sociolinguistic space for a European variety (or varieties) of English', given the fact that the UK will no longer serve as a gatekeeper on issues 'of correctness and standardization'. Here, he notes, the Kachruvian paradigm is not only relevant to Africa and Asia, but also to Europe, and he further argues that the conditions are set for the emergence and recognition of a distinct variety of 'Euro-English'.

Modiano then proceeds to develop his argument through a discussion of the politics of language within the EU, the notion of a 'second-language variety' of English in this context, English in European education, and, finally, the development of Euro-English.

This article is protected by copyright. All rights reserved. 
]p[On the first issue relating to the politics of language, the essential question is whether English will continue to be used as a working language of the EU once Brexit is complete. With reference to this issue, Modiano quotes from a number of press reports, which suggest that certain European politicians were already anticipating that English would lose its previously dominant status, not least because of a strongly perceived 'French aversion to English'. However, on balance, Modiano argues there is a good deal of evidence that English will maintain its current status within the EU, although, one major change that will occur will be 'a noticeable lack of L1 users of English present to influence the direction English is to take in the days and years ahead', thus liberating, as it were, the language from its previous association with the British so that in future, '[w]hen using English, EU citizens will all be on the same footing, that is to say, they will be communicating in an L2, and as such, only a relatively small number of people will have an unfair advantage' (Modiano, this issue). Anyway, he argues, the driving force for the spread of English in Europe is not the influence of the UK, but rather, the unstoppable power of globalization, not least among young people across Europe:

]ex[People in Europe have found, through English, an opportunity to communicate with others from throughout the world [...] Moreover, we are witnessing an increasing desire to acquire English among the youth of continental Europe, where participation in on-line activities, access to various forms of media, as well as the requirements of education, especially higher education, have made knowledge of English a must. (Modiano, this issue)

]fo[In this context, he maintains, the conditions are ripe for English to evolve in the same way as other 'second-language' varieties, and to experience nativization in similar fashion to Outer Circle varieties worldwide. In addition, he argues, the rising status of the English language in Europe will be further strengthened by its ongoing and increasing popularity within all levels of education within the EU. In the final section of his article, Modiano then argues for the reeognition of European English or 'Euro-English', which he initially explains with reference to the particular vocabularies of various sectors within the European population. This includes both the specific jargon of EU organizations, as well as lexical items, idioms, and proverbs linked to the specific cultures of European societies. In addition, Modiano also refers to particular grammatical structures, as well as patterns of pronunciation, noting that 'the strategies that continental Europeans deploy when using English will inevitably evolve differently in comparison to the strategies of Inner Circle users of English'. Here, he concedes that scholars working within the English as a lingua franca (ELF) approach have attempted to analyse such interactions, but dismisses this in a preference for the promotion of a 'European variety of English' (Euro-English). Finally, albeit optimistically, Modiano claims that English needs to be recognized as 'Europe's premier universal language', arguing for a vision of Euro-English that 'captures the very essence of liberation linguistics'.

\section{Jha[RESPONSES TO MODIANO'S ARGUMENTS}

]ro[In her response to Modiano, Margie Berns suggests that one key result of Brexit may be 'a weakening of the notions that English belongs to its native speakers and that English is inextricably tied to native speaker culture'. The removal, or at least weakening, of the link between English and Britain in the EU will then enable 'continental users [...] to shape their variety as a carrier of their values, traditions, and norms - that is, their sociolinguistic realities'. In time, such processes, Berns asserts, may well 'change the profile of English in Europe and foster the development of European English'.

This article is protected by copyright. All rights reserved. 
]p[David Crystal endorses Modiano's advocacy of a dynamic polymodel for EuroEnglishes, and even recognizes the relevance as such labels as 'Swedish English', 'French English', 'Chinese English', with reference to Expanding Circle users of the language. In the context of Europe (and elsewhere), Crystal further explains that 'local English' is typically expressed through 'a mix of local accent and lexicon, along with pragmatic and sociolinguistic factors (such as politeness norms), and some grammatical differences'. In addition, Crystal highlights the importance of cultural identity expressed in the 'vocabulary, idiom, and encyclopedic knowledge' of local speakers of English in particular contexts. Consequently, Crystal argues, 'Swedish English [...is] the cultural knowledge I need to have to make sense of what Swedish people are saying when they speak English to me in Sweden', particularly when discussing the local culture and realia of everyday life. In this context, however, Crystal raises the issue of whether the European Union can be regarded as a social group that has the shared cultural identity that might underpin a shared Euro-English, and suggests that evidence of local identities are found more readily at the national, rather than transnational (that is, EU) level. Indeed, the main evidence for shared linguistic norms, he suggests, is found only in the 'Eurospeak jargon' of the EU Parliament and its sister institutions. For this and related reasons, Crystal argues that the case for a single, monolithic variety of Euro-English is clearly flawed, and that ultimately it makes far more sense to argue for 'a multiglossic recognition of Euro-Englishes', in the 'new sociolinguistic space' of a reconfigured European Union.

Marc Deneire questions a number of Modiano's assumptions concerning this issue, crucially noting that the EU is by no means a united association, and that it is beset by many diverse divisions, both ethnically and politically. Deneire questions the wisdom of labelling European countries 'pro-English' or 'anti-English', and also challenges the notion that Europeans generally welcome English as the language of globalization, noting pointedly that the people who benefit from English proficiency are few, and even among them, many only reluctantly accept to use English when/because it is forced upon them'. Finally, Deneire dismisses the notion of Euro-English as a 'variety', and argues forcefully for a plurilingual vision for a multilingual Europe. Marinel Gerritsen, in her response, agrees with Modiano that English will remain the most important language in the European Union, but expresses strong doubts that the kind of 'Euro-English' Modiano describes will ever gain strong acceptance. One reason for this scepticism, she explains, is that proficiency in English across Europe is not as high as Modiano suggests, and points out that (in the Eurobarometer survey of 2012) 'only 24\% of EU citizens said they use English daily, and 23\% reported using it often, but not daily'. Gerritsen further notes that proficiency in the English language varies greatly from country to country, with nations like Hungary and Spain reporting general levels of ability much lower than those in the Netherlands or Scandinavia. For this reason, Gerritsen challenges the assumption that English is uncontroversially an L2 ('second language') variety throughout all the nations of the European Union, and further proceeds to argue that the emergence of an 'authentic' European English (or Euro-English) would also be hindered by the major differences between the two source language families of Europe, the IndoEuropean family and the Finno-Ugric family, so that the differences between speakers having different mother tongues are likely to persist whatever the future of the EU as a whole.

In her comments on the Modiano article, Jennifer Jenkins agrees that English will remain the principal working language of the EU in the period after Brexit, and also concurs that the style of English in the EU in the future is likely to diverge from 'native' British norms, but then takes some issue with Modiano's understanding of English as a Lingua Franca (ELF) in this context. Modiano's characterization and criticism of ELF as a putative 'variety' of English is, Jenkins explains, severely out-of-date, and ELF is today better understood as 'a complex adaptive system'. With reference to 'Euro-English', she asserts that only the 
'Eurospeak' of EU jargon can properly be regarded as a variety, as this has, to some extent, been documented as such. Otherwise, the argument is that current conceptualizations of ELF do have obvious applicability and relevance to communication within a linguistically-diverse European Union, and here Jenkins invokes Mauranen's (2012) notion of similects, where ELF is re-imagined as 'second-order language contact', and 'a contact between hybrids', or 'hybrid of similects' (Mauranen 2012: 29-30). Finally, Jenkins concludes that contemporary ELF studies are best understood as 'English within multilingualism', and that it is just this dimension of multilingualism that will constrain and influence the future use of English both inside and outside the EU in the years to come.

Robert Phillipson's reaction to the Modiano article explains that language policy in the EU should be analyzed with reference to both 'language rights' and 'language use in law and in practice'. Thus, he adds, decisions concerning language policy will apply somewhat differently to different stakeholders in the EU, including employees of the European Commission (Eurocrats), Members of the European Parliament, to the European Council of Ministers, as well as many other employees of EU organizations. The production of policy documents and EU legislation requires a massive effort in translation, while other EU activities require a parallel effort in interpretation services. All this contributes to a highly complex situation within the EU, little of which, Phillipson argues, is tackled in Modiano's discussion. He then proceeds to challenge a number of Modiano's points, including: (i) the unproblematized identification of English, French, and German as the 'three working languages of the EU; (ii) the blurring of EU and non-EU countries; (iii) the claim that English is a 'common continental European language', which ignores the fact that many other languages function as lingua francas; (iv) the claim that the French are guilty of an 'aversion to English'; and (v) the assumption that the British have acted as 'guardians' of the English language within EU institutions. Phillipson notes that ' $[\mathrm{t}]$ he language of EU documents is sui generis [... and that the] language is essentially a technical one for very specific purposes that attempts to navigate the turbulent waters of maintaining linguistic diversity, consistency in formulating EU principles, and respect for the principle that language, education, and culture are national rather than supranational prerogatives'. He is also highly skeptical that anything approximating to an authentic 'Euro-English' actually exists, noting that there is little evidence of an emerging European standard English, in terms of regularized features of vocabulary, grammar, spelling and punctuation. Finally, Phillipson argues, one of the most important issues here remains that of linguistic imperialism, as evidenced by the expansion of English within the EU as a result of European Commission policies (Phillipson 2016).

Mario Saraceni initially agrees with Modiano's conclusion that the importance of English is likely to continute in the EU after Brexit takes place, but he takes issue with Modiano's attempt to apply a WE framework to the analysis of English in Europe, and the advocacy of Euro-English. In this context, he suggests, there are three basic flaws in Modiano's argument. First, that any useful comparison may be made between English in Europe and post-colonial Englishes worldwide. Second, Saraceni suggests that it is misleading to confuse the fate of English within EU organizations with the currency and use of English in Europe outside such institutions. Third, Saraceni also takes strong issue with the label of 'Euro English', which like its correlate of 'British English' is sociolinguistically misleading given the constant flows and flux of English in contact with other languages domestically.

Edgar Schneider is also highly skeptical of the notion of 'Euro-English' ('an exotic, if elusive, animal'), but concedes that there are points of agreement concerning at least some of Modiano's claims, including the speculation that English will retain its status as the 'main lingua franca' in the European Union, and the status of English in European education systems is unlikely to be affected by Britain's exit from the Union. However, Schneider then takes issue with a number of points in the article, including the statistics on English speakers

This article is protected by copyright. All rights reserved. 
in Germany, as well as Modiano's dismissal of the relevance of English as a Lingua Franca (ELF) in the European context. ELF, he suggests, might be best understood in terms of the study of the use of English in 'socially-defined' contexts, and is 'a most important and timely enterprise', allowing for far greater flexibility than a rigid notion of 'Euro-English'. Schneider later goes on to argue that the Brexit vote in Britain may indicate a strong reaction against globalization and the possibility that 'the age of globalization is coming to a close', and that, simultaneously, 'the global hegemony of English [...] may be significantly reduced'. Despite that, Schneider remains confident that, whatever else in Europe, 'speakers will keep using their English for whatever purposes are at hand, largely independent of what happens in the corridors of Brussels'. For his part, Philip Seargeant suggests that we can only speculate about the implications of Brexit for the future role of English in Europe, while noting that the English language is often used as a 'symbolic touchstone' in debates of this kind. In addition, Seargeant makes three key points concerning Brexit and beyond. First, that while the UK may be leaving the EU, it will continue to be part of Europe; second, that one needs to distinguish between EU institutions and the actual citizens of the EU community; and, third, that European attitudes to the English language are likely to be shaped as much (or more) by the US than by relations with the UK.

Finally, in their commentary on the article, Barbara Seidlhofer and Henry Widdowson consider a number of Modiano's key arguments. He may well be correct, they concede, in suggesting that if Brexit uncouples English form the British, it can be 'appropriated' by members of the EU as their own means of communication, so that 'English can now be proclaimed as independent of Britain', which, in turn, may lead to 'a less inhibited expedient communicative use of the language and increasing variability in reference to the norms of Standard English', but, they suggest, nevertheless, 'it does not follow that this will result in the emergence of a distinct lectal variety, a European English analogous to other world Englishes' Seidlhofer and Widdowson then proceed to make the argument that Brexit will not (as Modiano claims) further the cause of the 'Euro-English', but, rather and far more likely, clear the space for 'a less inhibited and stigmatised use of English as a lingua franca (ELF)'. Ultimately, they suggest, the notion of an indigenized Euro-English would depend on common usage across the EU, which seems unlikely given current moves towards increased diversity and divisions within the European community.

\section{|ha[IN SEARCH OF 'EURO-ENGLISH'}

]ro[In Modiano's article, and in the responses to it, there is much discussion regarding the existence or absence of a distinct variety of European English or 'Euro-English'. However, few examples of this variety are actually cited by either Modiano or his discussants, although passing reference is made by a number of contributors to the 'Euro-English' of the European Union. One rather rich resource for examining Eurospeak, as it is sometimes called, is provided by an online guide to 'Misused English words and expressions in EU publications', compiled by Jeremy Gardner, a senior translator at the European Court of Auditors. From a WE perspective, this glossary provides an interesting guide to some of the distinctive 'features' of EU English, particularly at the level of vocabulary. At the same time, Gardner's own commitment to identify and discuss the misuse of English is based on a clear commitment to a UK standard of English, as he himself explains:

]ex[Over the years, the European institutions have developed a vocabulary that differs from that of any recognised form of English. It includes words that do not exist or are relatively unknown to native English speakers outside the EU institutions and often even to standard spellcheckers/grammar checkers ('planification', 'to precise' or 'telematics' for example) and words that are used with a meaning, often derived from other languages, that is not usually found in English dictionaries. [...] However, our

This article is protected by copyright. All rights reserved. 
publications need to be comprehensible for their target audience, which is largely British and Irish, and should therefore follow a standard that reflects usage in the United Kingdom and Ireland. (Gardner 2016: 3, emphasis in the original)

]fo[Examples of EU-English of this kind are set out in Table 1, where the original Euro expression is accompanied by a gloss in a standardized form of UK English.

$<$ Table 1 near here $>$

]th[Table 1.Examples of jargon commonly used by European Union officials (Gardner 2016)

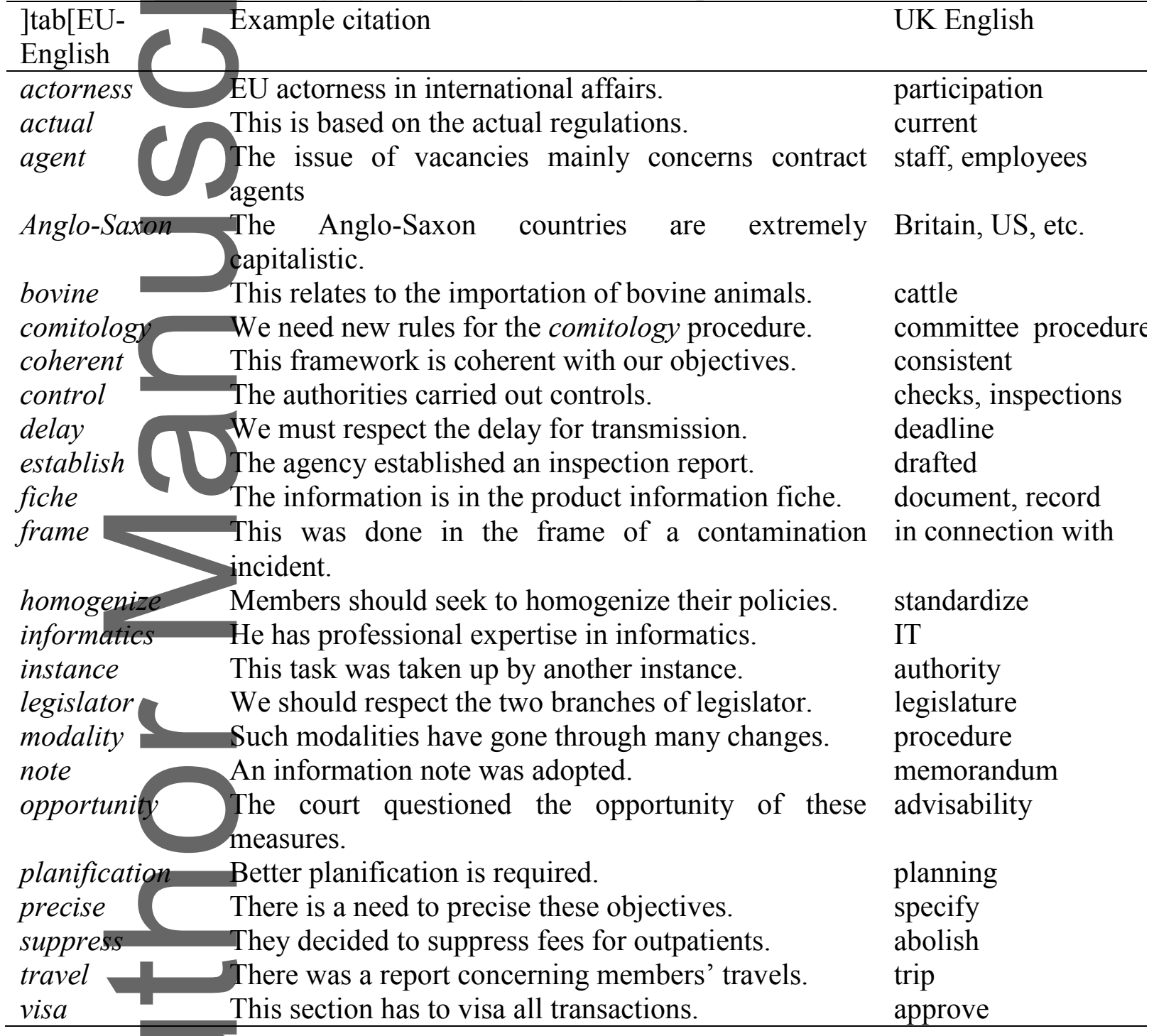

]p[Some of the most striking terms in the above list include such items as agent, AngloSaxon, control, comitology, fiche, modality and visa. In general usage, agent is a word typically applied to a business representative of some kind, whereas, in EU usage it is usually refers to 'someone who is employed by the EU in any capacity'. The term Anglo-Saxon in the $\mathrm{EU}$ is used to refer to both to dominantly Anglophone societies, or, often inaccurately, to Inner Circle citizens. Control is used to convey the meaning of 'check' or 'verify', rather than its usual sense of 'exert a dominant influence over'; comitology refers to 'committee procedures and protocols' within the EU; fiche is a French word for 'document' or 'record';

This article is protected by copyright. All rights reserved. 
and a modality is a certain 'method' or 'procedure'. The term visa is generally used to express 'approval', although this word may also be used as a verb, as in Table 1.

While the examples in Table 1, and the work from which this is taken, may convey the flavor of jargon within EU institutions, they represent only a small part of communication in English within the European community, where English is more widely employed as the common link language in such contexts as higher education, international business, tourism and a wide range of other activities. In connection with such everyday uses of language, the question is then raised of exactly what kind of English (in linguistic terms) we expect to be spoken by European 'second language' speakers of English when communicating with one another. It is perhaps here that we may look to research from ELF scholars for insight into the linguistics of language contact in such contexts, given that Europe has been the site of much of the pioneering research on English as a lingua franca. Indeed, earlier research on ELF features goes some way to providing a description of such contact features, including, somewhat fämously, Jenkins' (2007) description of Lingua Franca Core Phonology (with its distinctive TH-stopping), as well as Seidlhofer's (2004) description of potentially 'salient features of ELF grammar', including such items as:

]ex[- the non-use of the third person present tense-s ('She look very sad');

- interchangeable use of the relative pronouns who and which ('a book who', 'a person which');

- omission of the definite and indefinite articles;

- use of an all-purpose question tag such as isn't it ? or no?;

- inserting redundant prepositions ('we have to study about the book');

- the frequent use of verbs of high semantic generality, such as do, have, make, put, take;

- replacing infinitive-constructions with that-clauses, as in 'I want that';

- overdoing explicitness (for example, 'black color' rather than just 'black').

(Seidlhofer 2004:220)

]fo[In addition, at the level of vocabulary, one might also expect ELF speakers to use a smaller word stock than many first-language users of the language, and also to avoid, or even to amend, the use of culturally-loaded idioms and other references. In addition, at the level of discourse, a number of communicative strategies have also been described as characteristic of ELF communication. These were concisely summarized by Kirkpatrick (2010) as including 'lexical anticipation'; lexical suggestion'; the 'don't give up' strategy'; the 'request for repetition'; the 'let it pass' strategy; the 'making explicit' strategy; and 'participant paraphrase' (Kirkpatrick 2010: 127-136).

]p[In very simple terms, then, the kind of linguistic model one might expect from an ELF view of Euro-English(es) would be one where many or most speakers retain a secondlanguage accent, where their speech routinely contains a good many 'salient' grammatical ELF/interlanguage forms, but also one where speakers, more or less adroitly, deploy a range of creative strategies in order to communicate effectively. However, this somewhat simplified account of ELF features is drawn from early studies within this area (Jenkins, this issue), and today the ELF conceptualization of its research field has moved on to substantially nuance and redefine the object of study. Indeed, in a recent discussion of ELF theory, Jenkins is keenly concerned to reframe the study of English as a Lingua Franca (ELF) as 'ELF 3' or 'English as a Multilingua Franca', claiming that, while ELF 1 was concerned with description, and ELF 2 with variability, ELF 3 is concerned with multilingualism. Here, Jenkins argues:

] ex[English, while always in the (potential) mix, is now conceived as one among many other languages, one resource among many, available but not necessarily used, with ELF defined not merely by its variability but by its complexity and emergent nature. [...] It is thus ELF-using monolingual use that is 'marked' and ELF-using multilingual use that is 'unmarked'. This means, in turn, that in ELF

This article is protected by copyright. All rights reserved. 
communication, monolingual speakers are disadvantaged relative to multilingual speakers, and need to learn other languages so as to be able to participate fully in ELF. (Jenkins 2015: 77-78)

]fo['English as a Multilingua Franca,' Jenkins notes, may be now defined as 'multilingual communication in which English is available as a contact language of choice, but is not necessarily chosen' (73). Thus she explains:

]ex[In other words, English as a Multilingua Franca refers to multilingual communicative settings in which English is known to everyone present, and is therefore always potentially 'in the mix', regardless of whether or not, and how much, it is actually used. It follows from this that instead of talking about ELF users [...] we can talk about 'ELF-using multilinguals' and 'ELF-using monolinguals', or 'Multilingual ELF users' and 'Monolingual ELF users'. (Jenkins 74)

]fo[In this recast approach to ELF, a number of points now follow, including the recognition of multilingualism as the 'superordinate', and a downsized role for ELF as 'English' in lingua franca contexts, notwithstanding the fact that the language is always 'potentially' present and 'in the mix', where linguistic resources are 'repertoires in flux' and part of the mobile resources of lingua franca users.

Where this leaves the 'English' element of ELF in the European context is some distance from the simplified ELF model sketched out above. Indeed, it leads us away from the consideration of a Euro-variety of English to the complex multilingual ecology of $24 \mathrm{EU}$ member states, with scores of official, unofficial, and minority languages across the European Union. In fact, one of the most interesting questions to emerge from Modiano's original discussion paper is that of the somewhat elusive notion of 'European English'. If this does exist, as a yariety, lect, or even 'similect', how can this - in linguistic terms - best be described? This issue is at the heart of Modiano's article, and is present in virtually all of the discussions we present below. The fact that this question eludes easy description should not detract from its pertinence, and not least for its utility in stimulating the fascinating discussion that follows, around this as well as a cluster of related issues, in this forum on English in a post-Brexit European Union.

\section{Jha[CONCLUSION}

]ro[In recent months, as we have moved towards the publication of this special forum, discussions of the fate of English in a post-Brexit Europe have continued to surface in the international press. In early May of 2017, Jean-Claude Juncker, the President of the European Commission, caused a flurry of press activity when, in a key speech shortly before the French Presidential election, he declared that 'slowly but surely, English is losing its importance in Europe', before switching to French for the rest of his speech (Kanter \& Wolgelenter 2017). Despite this, some commentators seem convinced that English will continue to spread throughout Europe, reporting that, across the EU, 97 per cent of lower secondary students are learning English, compared with 34 per cent for French and 23 per cent for German. At primary school 79 per cent are learning English, compared with only 4 per cent for French (The Economist 2017). A number of others have been somewhat less sanguine concerning the linguistic consequences of Brexit, even suggesting that one hitherto unforeseen consequence of Britain's exit from the Union may be a growing political desire to gain de jure recognition of English as the main official language of the UK, as recognition has already been given to Welsh in Wales and Scottish Gaelic in Scotland. In addition, there may also be consequences for other minority languages in the UK, including the status of Irish in Northern Ireland, as well as the languages of immigrant communities (Jones 2017).

This article is protected by copyright. All rights reserved. 
]p[At present, the political process of Britain's exit from the European Union is a work-inprogress that has only just begun, and although the UK is simply exiting the EU, rather than Europe in some wider sense, many see this as a momentous political event, likely to bring with it many cultural, economic, and social consequences in future. Exactly what this will mean for English, or perhaps more importantly, the wider multilingual ecology of Europe, remains to be seen, but it is hoped that the discussions and debates presented in this forum will provide many useful insights into a key sociolinguistic issue that will continue to attract attention for many years to come.

\section{]ha[REFERENCES}

]ref[Chazan, Guy \& Jim Brunsden. 2016. Push to bid adieu to English as EU's lingua franca. Financial Times. https://www.ft.com/content/e70b5042-3c65-11e6-8716-a4a71e8140b0 (15 June, 2017.)

Daily Express. 2016. English should be BANNED in Brussels after Britain leaves, top French politician insists. Express. http://www.express.co.uk/news/world/683980/english-bannedbrussels-britain-leaves-jean-luc-melenchon-brexit (15 June, 2017.)

Gardner, Jeremy. 2016. Misused English words and expressions in EU publications. Brussels: European Court of Auditors.

Jenkins, Jennifer. 2007. English as a lingua franca: Attitude and identity. Oxford: Oxford University Press.

Jenkins, Jennifer. 2015. Repositioning English and multilingualism in English as a Lingua Franca. Englishes in Practice 2(3). 49-85.

Jones, Lowri. 2017. Brexit and language: What future for English and for the minority languages of the UK? http://blogs.cardiff.ac.uk/brexit/2017/05/11/brexit-and-languagewhat-future-for-english-and-for-the-minority-languages-of-the-uk/ (15 June, 2017.)

Kanter, James \& Michael Wolgelenter. 2017. E.U. leader says (in English) that English is waning. The New York Times. https:/www.nytimes.com/2017/05/05/world/europe/jeanclaude-juncker-eu-english.html?_r=0 (15 June, 2017.)

Kirkpatrick, Andy. 2010. English as a lingua franca in ASEAN: A multilingual model. Hong Kong: Hong Kong University Press.

Seidlhofer, Barbara. 2004. Research perspectives on teaching English as a lingua franca. Annual Review of Applied Linguistics 24. 209-239.

Steinhauser, Gabriele. 2016. English loses currency as Europe's lingua franca after Brexit vote. Wall Street Journal. https://www.wsj.com/articles/eu-to-say-au-revoir-tschuss-toenglish-language-1467036600 (15 June, 2017.)

The Economist. 2017. Britain is leaving the EU, but its language will stay. The Economist. http://www.economist.com/news/europe/21721861-despite-jean-claude-junckers-jokeangtophones-should-rest-easy-britain-leaving-eu-its (15 June, 2017.)

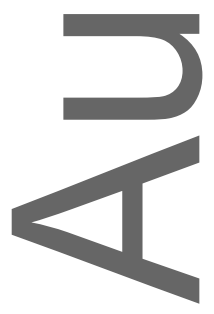

]rec[(Received 1 June 2017)

This article is protected by copyright. All rights reserved. 